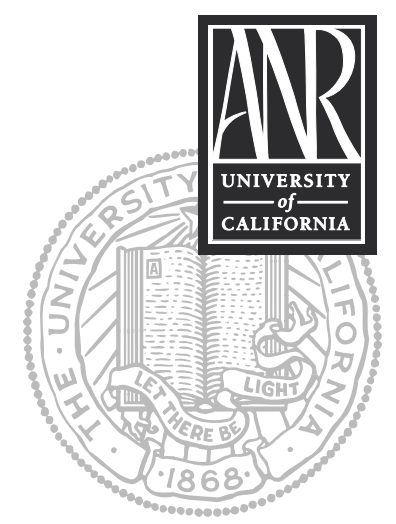

UNIVERSITY OF CALIFORNIA

Division of Agriculture and Natural Resources http://anrcatalog.ucdavis.edu

\title{
Selling Meat and Meat Products
}

LINDA J. HARRIS is Cooperative Extension Specialist in Microbial Food Safety, Department of Food Science and Technology, UC Davis, and HSU LING TAN is Planning Analyst, Strategic and Business Development, Sutter Health.

\section{INTRODUCTION}

Before you can legally offer domestic meat and meat products for sale, the meat animal must be slaughtered in a facility inspected by U.S. Department of Agriculture's Food Safety and Inspection Service (referred to simply as USDA in this publication) (Title 9, Code of Federal Regulations, part 417; or, more briefly, 9 CFR 417). In addition, products processed from USDA-inspected carcasses must be handled in a facility inspected by either county, state, or USDA inspectors, depending upon the type of product and the intended customer. This publication provides an overview of the meat and poultry inspection system in California.

\section{SELLING THE CARCASS}

\section{Federal Inspection for Slaughter}

Federal inspection by USDA inspectors is required for cattle, swine, sheep, goat, equines (horses, mules, ponies, and burros), and in many cases poultry (see below). You can only sell meat from these animals if they are slaughtered in a USDA-inspected facility (Figure 1).

When an animal is to be sold as meat, USDA ante- and post-mortem inspections are mandatory for

- "Amenable livestock species" (cattle, swine, sheep, goat, and equines)

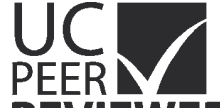
REVIEWED
- "Amenable poultry" (turkeys, chickens, ducks, geese, squab, guinea fowl, and ratites [emus, rhea, and ostrich]), for plants slaughtering more than 20,000 poultry carcasses per year (9 CFR 381.10(b) (1)).

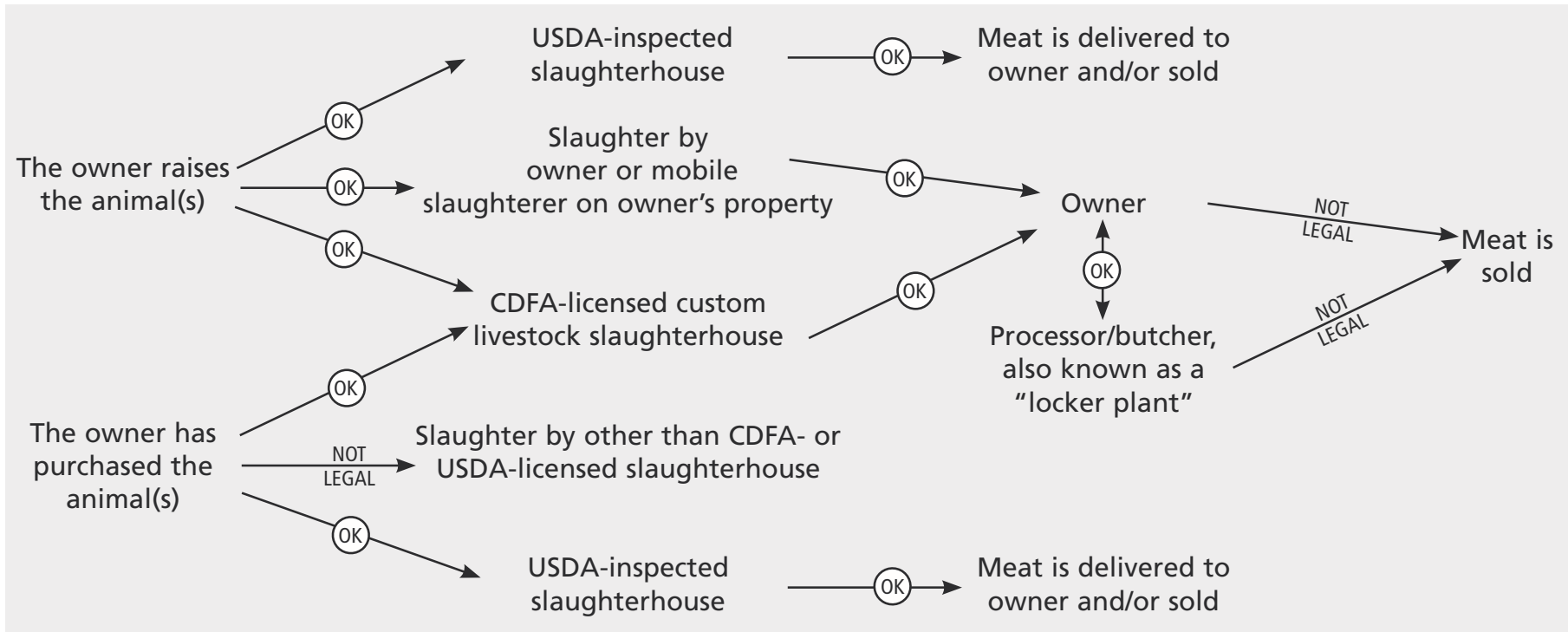

Figure 1: Schematic diagram for livestock slaughter transactions in California. Federal inspection is provided by the USDA Food Safety and Inspection Service (indicated here as USDA), and state inspection is provided by the California Department of Food and Agriculture (CDFA), Meat and Poultry Inspection Branch. 
Growers can request voluntary, fee-based USDA inspection for:

- Products from non-amenable or exotic species (e.g., reindeer, elk, deer, antelope, water buffalo, or bison [9 CFR 352.1])

- Rabbit

- Poultry (fewer than 20,000 poultry carcasses)

- Migratory waterfowl or game birds (9 CFR 362)

While legal in some states, the slaughter or selling of horsemeat in California is prohibited. It is a felony in California to buy, sell, or obtain horses, ponies, burros, or mules for the purpose of slaughtering for human consumption, and a misdemeanor to offer horsemeat for sale (California Penal Code 598(c)). USDA-inspected equine slaughterhouses currently exist in Texas, Idaho, Nebraska, and Illinois.

\section{State Inspection for Slaughter}

The California Department of Food and Agriculture (CDFA) Meat and Poultry Inspection Branch conducts inspection for the following:

- livestock slaughter plants that custom-slaughter cattle, sheep, swine, and goats raised by owners or purchased live. This meat is to be used by the owner or the owner's family, nonpaying guests, or employees. The meat cannot be sold.

- poultry plants that slaughter species not subject to USDA inspection, such as rabbit, quail, partridge, and other domesticated fowl

- farm-raised fallow deer brought live to slaughter

- retail poultry plants that sell live poultry and slaughter them for their customers

- non-retail poultry plants that slaughter or process fewer than 20,000 poultry carcasses a year (see below)

\section{CDFA Inspection for Fewer than 20,000 Poultry Carcasses per Year}

Inspection requirements differ according to the size of the farm. If it is a family-run farm without hired help,

- In some counties, no inspection is required if poultry is sold from the farm or at farmers markets and fairs. Check with the specific county's Department of Environmental Health.

- State inspection is required if the meat is to be sold to retail stores and restaurants.

If it is a family-run farm with hired help,

- State inspection is required. In some counties, the state inspection requirement is waived if the entire output is sold directly to consumers at the farm. Check with the specific county's Department of Environmental Health.

- Growers may be able to opt for voluntary (fee-based) USDA inspection.

Regardless of whether the owner uses hired help, he or she has the option to take birds to a state-inspected facility for slaughter. Slaughtered carcasses can then be picked up from the facility on ice and sold.

CDFA inspection review is also available for the following:

- meat inspection systems of other states and of foreign countries desiring to ship slaughtered non-amenable species to California.

- slaughtered non-amenable poultry species shipped to California from other states and countries.

- sanitation and records of custom-exempt establishments (locker plants that cut, wrap, and process meat from on-farm killed livestock). 


\section{SELLING PROCESSED MEATS}

Processed meat products are anything other than the carcass itself (for instance, cuts, ground meat, sausage, jerky, and marinated meats). Products that contain relatively small proportions of meat are exempt. These include any foods that contain less than $2 \%$ cooked meat or cooked poultry or less than 3\% raw meat by weight. Details can be found in 9 CFR 381.15(a).

For processed meat products, the following apply (Figure 2):

- All meats used in the processed product must be USDA-inspected. The animal MUST have been slaughtered in a USDA-inspected facility.

- A retail facility may process and sell USDA-inspected cuts of meat or ground product. Retail sale is defined as selling to the final consumer on the premises where the product was produced or on other premises under the control of the processor. The local County Department of Environmental Health will inspect the facility as a retail store.

- If a retail facility prepares and sells USDA-inspected meat or poultry products by curing, smoking, drying, or rendering, or if it cooks pork products, the facility MUST be inspected by the CDFA.

- If products are sold wholesale (to someone other than the final consumer) they MUST be processed in a USDA-inspected facility.

\section{IMPORTING MEAT OR MEAT PRODUCTS FOR SALE OR FURTHER PROCESSING}

Meats or meat products can only be imported into the United States if they were processed in foreign facilities that are certified to export to this country. For details online, see http://www.fsis.usda.gov/OPPDE/IPS/Importing.htm.

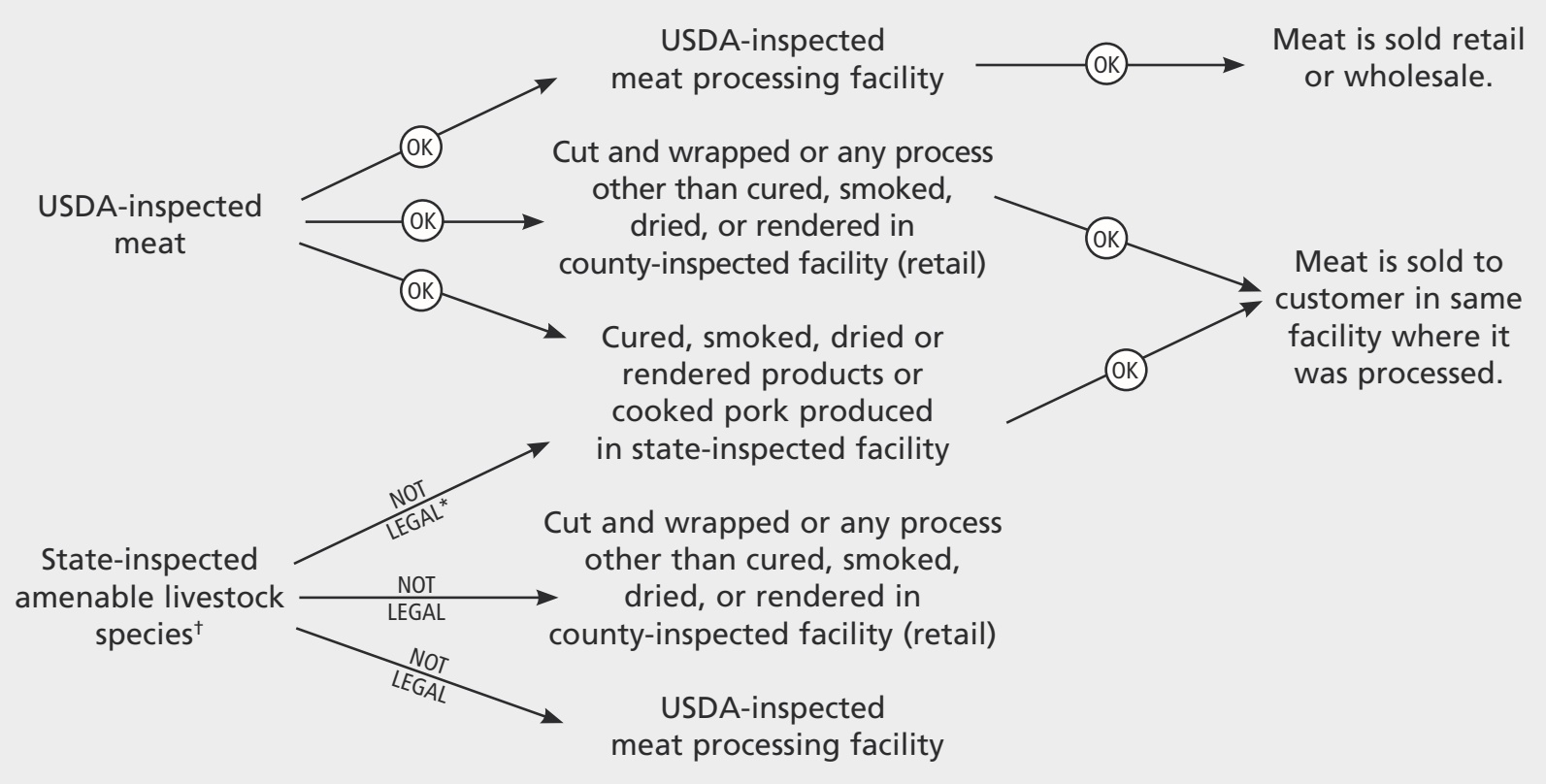

Figure 2. Schematic diagram of inspection requirements for selling processed meats in California. *In California, fallow deer is the only species that can be sold after slaughter in a state-inspected slaughterhouse and processing in a state-inspected processing plant.

'State-inspected livestock can be further processed in state- or county-inspected facilities if the products are for personal use only. The products cannot be sold. 


\section{SLAUGHTERING AND PROCESSING EXOTIC SPECIES}

Some animal species not covered above are sold as meat in specialty markets. They sometimes are referred to as exotic species, although they may be commonly consumed in other countries. Exotic animal species (e.g., iguana or guinea pig) do not fall under USDA or CDFA jurisdiction. Instead they fall under the jurisdiction of the U.S. Food and Drug Administration (FDA) and in California the Department of Health Services Food and Drug Branch (DHS FDB). The FDA and the DHS FDB are responsible for inspection of seafood and all non-meat or non-fluid milk products, but because exotic land animal species are not under the jurisdiction of either the USDA or the CDFA, they fall to FDA and DHS FDB oversight even though they are meat products. Exotic aquatic species such as alligator, frog, and turtle are inspected by the FDA under the seafood inspection regulations (21 CFR 123).

Exotic species have to be slaughtered in a facility that conforms to Good Manufacturing Practices (GMP) regulation 21 CFR 110. In California, the facility that slaughters and processes the meat will need to be a registered food-processing establishment. See web links below for details on how to register as a California Department of Health Services Food and Drug Branch Inspected Facility. A USDAinspected facility may provide services for slaughtering these animals, but this would be done either as a specifically requested, fee-based inspection or separately from the USDA inspection (with the knowledge of the USDA inspectors).

If you purchase exotic meat to sell or for further processing, it must be from an approved source. This means that the animal was slaughtered, dressed, and processed (if applicable) under an inspection system recognized by the CDFA, USDA, or USFDA (see above for information on importing meat). Exotic meats imported from other countries or states may be rejected if there is not proof of adequate inspection. If you import farm-raised live animals with the intention of selling the meat for human food, make sure the animal is not on the endangered species list by checking with U.S. Fish and Wildlife Service (http://www.fws.gov). Make sure that the animal was raised as a food animal with adequate attention to required antibiotic or other drug use and withdrawal times.

In California it is also a misdemeanor to sell, buy, give away, or accept any carcass or carcass part of an animal traditionally or commonly kept as a pet or companion with the intent of using any part of the carcass for food. This does not apply to livestock, poultry, fish, shellfish, or other agricultural commodities (California Penal Code Section 598(b)).

\section{GLOSSARY}

Amenable livestock species. Cattle, swine, sheep, goats, horses, mules, and other equines. USDA requires and provides antemortem and postmortem inspection of these species as a condition for retail sale.

Custom exempt slaughter facility. An establishment or part of an establishment that provides slaughter and/or processing services to livestock owners. Meat from animals slaughtered in this way can be further processed by a processor or butcher (locker plant), but neither the carcass nor the meat can be sold. These facilities are exempted from mandatory USDA inspection. They are licensed and inspected by the CDFA.

Locker plant. A licensed business that provides butchering services to break down the carcass into various cuts of meat. The CDFA reviews sanitation and records of these facilities. These facilities often have lockers that are available for rent for frozen storage of food for human consumption (frozen locker plant). 
Mobile or itinerant custom slaughterer. A business that provides on-farm slaughter for persons who raise animals. In California, these businesses must be registered with the CDFA. Meat products from animals slaughtered in this way are intended for the owner's household consumption only or for the consumption of non-paying guests and non-paying employees. The meat can be further processed by a processor or butcher (locker plant), but neither the carcass nor the meat can be sold.

Non-amenable species. Any species other than cattle, sheep, swine, goats, horses, mules, other equines, ratites (emus, rhea, and ostrich), and domesticated poultry (turkeys, chickens, ducks, geese, and guinea fowl). Examples of non-amenable species include bison, deer, quail, and rabbit. The USDA does not require antemortem and postmortem inspection of non-amenable species as a condition for retail sale as it does for amenable species. A producer or processor can voluntarily request USDA inspection of non-amenable species for a fee. The CDFA also licenses and inspects facilities that slaughter non-amenable species.

Retail-exempt. A retail facility or part of a facility that further processes meat and is exempt from USDA or CDFA inspection, but is subject to county inspection (usually by the county's Department of Environmental Health). These facilities must exclusively use USDA-inspected meat or carcasses. Processing can include cutting and wrapping or any process other than producing a cured, smoked, dried, rendered product, or cooked pork. Many supermarkets with fresh meat and deli cases fall into the retail-exempt category.

\section{RELATED WEBSITES:}

UC Food Safety. Information and links of general interest to food processors, including links to food processing registration and Good Manufacturing Practices regulations. http://ucfoodsafety.ucdavis.edu

HACCP. Information on hazard analysis and critical control points (HACCP). (The USDA meat and poultry inspection system and the FDA seafood inspection system are based on HACCP.) http://ucfoodsafety.ucdavis.edu/HACCP_Information/

Getting Started in the Food Business. Food regulations for food processors, including current Good Manufacturing Practices (21 CFR 110). http://ucfoodsafety.ucdavis.edu/Getting_Started_In_The_Food_Business/Food_ Regulations_-_Food_Processing_Facilities.htm

USDA-FSIS. Information on HACCP as well as labeling and other regulatory requirements for meat and poultry. http://www.fsis.usda.gov

FOCUS on Ratites. Information on ratites (emus, ostrich, and rhea). http://www.fsis.usda.gov/Frame/FrameRedirect.asp?main=/oa/pubs/ratites.htm

MPI. CDFA Meat and Poultry Inspection. http://www.cdfa.ca.gov/ahfss/mpi/index.htm

Custom Slaughterers/Itinerant Butchers and Licensed Frozen Food Locker Plants. Bureau of Livestock Identification requirements for custom slaughterers, butchers, and locker plants. http://www.cdfa.ca.gov/ahfss/li/slaughterers.htm

\section{REGULATORY REFERENCES}

Regulations can change. Before producing a meat or poultry product, review current regulations or consult with someone familiar with meat and poultry regulations.

Federal regulations cited in this publication are most easily accessed at this website: http://www.gpoaccess.gov/cfr/index.html (It is easiest to browse by title and chapter.)

The California Penal Code can be found at this website:

http://www.leginfo.ca.gov/calaw.html (Check "Penal Code" and search by section number for "598.") 


\section{ACKN OWLEDGMENTS}

Input from Holly George, Livestock Advisor, Plumas-Sierra Counties is gratefully acknowledged. Many helpful suggestions and regulatory information were provided by CDFA-Meat and Poultry Inspection branch veterinarians.

\section{FOR MORE INFORMATION}

You'll find detailed information on many aspects of livestock management and human nutrition and health in these titles and in other publications, slide sets, CD-ROMs, and videos from UC ANR:

Key Points of Control and Management for Microbial Food Safety: Information for Growers, Packers, and Handlers of Horticultural Products, Publication 8102 Maintaining the Competitive Edge in California's Beef Industry, Publication CPE-1 Quality Certification Program for Feedlot Operations: Feed Handling, Video V95-AW

To download these products, visit our online catalog at http://anrcatalog.ucdavis.edu. You can also place orders by mail, phone, or FAX, or request a printed catalog of publications, slide sets, CD-ROMs, and videos from

University of California

Agriculture and Natural Resources

Communication Services

6701 San Pablo Avenue, 2nd Floor

Oakland, California 94608-1239

Telephone: (800) 994-8849 or (510) 642-2431, FAX: (510) 643-5470

E-mail inquiries: danrcs@ucdavis.edu

An electronic version of this publication is available on the ANR Communication Services Web site at http://anrcatalog.ucdavis.edu.

\section{Publication 8146}

(C) 2004 by the Regents of the University of California, Division of Agriculture and Natural Resources. All rights reserved.

The University of California prohibits discrimination or harassment of any person on the basis of race, color, national origin, religion, sex, gender identity, pregnancy (including childbirth, and medical conditions related to pregnancy or childbirth), physical or mental disability, medical condition (cancer-related or genetic characteristics), ancestry, marital status, age, sexual orientation, citizenship, or status as a covered veteran (covered veterans are special disabled veterans, recently separated veterans, Vietnam era veterans, or any other veterans who served on active duty during a war or in a campaign or expedition for which a campaign badge has been authorized) in any of its programs or activities.

University policy is intended to be consistent with the provisions of applicable State and Federal laws.

Inquiries regarding the University's nondiscrimination policies may be directed to the Affirmative Action/Staff Personnel Services Director, University of California, Agriculture and Natural Resources, 300 Lakeside Drive, 6 ${ }^{\text {th }}$ Floor, Oakland, CA 94612-3550, (510) 987-0096. For information about obtaining this publication, call (800) 994-8849. For downloading information, call (530) 754-5112.

pr-11/04-WJC/CR

ISBN 978-1-60107-317-4

This publication has been anonymously peer reviewed for technical accuracy by University of California scientists and other qualified professionals. The review process was managed by the ANR Associate Editor for Animal, Avian, Aquaculture, and Veterinary Sciences. 